\title{
M-learning Modes for Language Learning on Blended Learning Theory

\author{
Li Ping
}

Applied Foreign Languages Department, Wuhan Business University, Wuhan, 430056, China

email:820535273@qq.com

Keywords: blended learning theory; language learning; m-learning modes.

\begin{abstract}
Mobile devices and advanced information technology have exerted profound influence on educational resources, contents, methods and modes in language learning. M-learning came into being due to its low cost and high portability. Through M-learning, students can learn at their own pace, at any time and anywhere. Thus their autonomy in language learning can be greatly enhanced. Under the guidance of blended theory, five kinds of m-learning modes such as mobile device assisted classroom learning, self-learning, SMS assisted learning, exploratory learning and collaborative learning are presented and commented for teachers and students to achieve successful language teaching and learning.
\end{abstract}

\section{Introduction}

M-learning offers a powerful and practical solution to many learning and training challenges. The first instance of mobile learning dates back as far as 1901 when Linguaphone( a company) released a series of language lessons on wax cylinders. Over the past ten years, with the European Commission funding the major multi-national MOBIlearn and M-learning projects, mobile learning has grown from minor researches to a set of significant projects in schools, universities and work places around the world.

The term M-learning or "mobile learning”, has different meanings for different communities and people. One definition of mobile learning is, "any sort of learning that happens when the learner is not at a fixed, predetermined location, or learning that happens when the learner takes advantage of the learning opportunities offered by mobile technologies."[1] Simply speaking, M-learning is the use of mobile technologies to enhance the learning experience. Mobile phones, PDAs, Pocket PCs and the Internet can be blended to engage and motivate learners to learn, at any time and any place.

For Chinese students, who learn English as a foreign language, their classroom learning hours are very limited, and after class they have few opportunities to practice English with native speakers. Under this circumstances, m-learning, covenient and accessible from virtually anywhere, can offer more effective and entertaining experience for studengts with differnt levels of English. This kind of leanring experience has many benefits to students. For one thing, they can forn the habit of taking charge of their own learning, and improve their learning autonomy. For another, M-learning can benefit them for continued education and life-long learning.

\section{Blended Learning theory}

The concept of blended learning emerged at the end of 20th century with the rapid application of e-learning in education. Since the 1990s, many experts and researchers have been working on the combination of traditional classroom learning with virtual learning. Thus blended learning came into being.

Till now, there has not been an established definition of blended learning theory. Different scholars have different ideas about it. Driscoll [2] thinks that blended learning means different things to different people. It means: a. Combining web-based technology to accomplish an educational goal; b. combining pedagogical approaches to produce an optimal learning outcome with or without instructional technology; c. combining any form of instructional technology with 
face-to face instructor-led training. Valiathan[3] states that it is: a. skill-driven learning, which combines self-paced learning with its instructor or facilitator support to develop specific knowledge and skills; b. attitude-driven learning, which mixes various events and delivery media to develop specific behaviors; and c. competence-driven learning, which blends performance support tools with knowledge management resources and mentoring to develop workplace competencies. According to the above mentioned definitions, at least two things are clear. One is that blended learning is a form of education that mixes E-learning with traditional face-to-face learning, which is a mix of media and learning approaches; the other is that it mixes teacher guidance with students' autonomous learning.

\section{The necessity of M-learning on blended Learning theory}

\section{A. The Present Situation}

Many Chinese college graduates, after having learned English for about ten years, have low proficiency in English speaking and writing. In traditional classrooms, learners are rarely encouraged to make use of their language skills in the real world. The only practice they have is in class. When they communicate with foreigners in English, it is difficult for them to speak approapriately in certain situation. So they fail to achieve effective communication. This symbolizes the failure of college English teaching. The inadequate teaching hours of English per week (4-5hours) fail to develop students' learning autonomy and linguistic competence. Meanwhile, quite a lot of students say they have enough free time for them to spend, but they don't know what to do, and most often, they feel empty. They need help from their teachers to guide them to learn after class. Meanwhile, the widespread use of mobile phones (nearly $99 \%$ of students own a mobile phone) makes it possible for students to conduct M-learning under the lead of their teachers. As mentioned by David Nunan[4], "one of the things that characterizes good language learners is their ability to find opportunities to activate their language outside of their classroom.” It is modern information technology that offers them the opportunity.

B. The Advantages of M-learning

The use of mobile learning in language learning is becoming increasingly common due to low cost, high portability and multifunction. The advantages are as follows: a. Mobile devices are cheaper than PCs and laptops which can be afforded by students; b. Cell phones or smartphones, multi-game devices, personal media players (PMPs), personal digital assistants (PDAs), and wireless single-purpose devices used are more lightweight than books and PCs. Therefore, they can be taken anywhere. c. The use of mobile devices via multimedia technology makes it accessible for students to do listening, speaking, reading, writing and translating practice. Thus it can enhance and support more traditional learning modes. d. Students can achieve multidirectional communication with their peers and instructors, receiving instant feedback and tips. Sharing is almost instantaneous among everyone using the same content.

\section{M-learning Modes on Blended Learning Theory}

\section{A. Mobile Device -Assisted Classroom Learning}

In traditional classroom, teacher is the center of the classroom. Teacher controls everything. A teacher is an instructor who speaks, and shows students important language points for students to take notes. Students are listeners and followers, who take a passive part in the classroom. Innovation can be made in classroom learning. Students are encouraged to use handheld computers, PDAs (personal digital assistant) or smartphones in a classroom or lecture room. If necessary, they can look up some new words in E-dictionaries, surf the internet and download some useful information or even record lectures while they are listening to the lecture. By doing so, students take an active part in classroom. They are active problem solvers instead of passive receivers. Their interest in English learning will be stimulated. Take podcasting for example. Podcasting consists of listening to audio recordings of lectures. Students can download a series of audio broadcasts onto a digital media player. These can be watched or listened to when, where and as often as students 
choose. It can be used to review live lectures and to provide opportunities for students to rehearse oral presentations. According to students, podcasts are more effective revision tools than their textbooks and their own notes in helping them to learn.

B. Self-learning Based on LAN(local area network)

Teachers and students can build a virtual classroom via LAN. Online course platform is provided for teachers and students to use at any time and anywhere.The platform contains three parts: a. study content; b. assessment content; c. feedback content.

a. Study Content

Three levels (preliminary, middle and advanced) of coursewares are offered for students to learn after class. The coursewares consist of listening, speaking, reading and writing materials. Students are asked to start from the level suitable for them. They can not jump lessons. They need to learn step by step.

b.Assessmet Content

After students finish learning one lesson, they will take a on-line exam to check their learning effect. If they pass the exam, they can move on; if not, they have to learn the previous lesson again. This will force students to learn sincerely and carefully.

c. Feedback Content

If students have questions in learning, they can ask questions and teachers will answer back on line.Teachers can also track students' learning records to know about students' learning speed and result, and accordingly modulate classroom teaching.

C. Short Message Service (SMS) Assisted Learning

Short Message Service (SMS) is a text messaging service component of phone, web, or mobile communication systems, using standardized communications protocols that allow the exchange of short text messages between fixed line or mobile phone devices. SMS is the most widely used data application in the world, with 3.6 billion active users, or $78 \%$ of all mobile phone subscribers[6]. Likewise, it is also frequently used by students due to its accuracy and promptness. Students have formed the habit of reading short messages wherever they are.

The learning mode based on SMS can promote communication between teachers and students beyond the limit of time and place.

Teaching and learning activities based on SMS include: (1)The college issues teaching activities announcements; (2)Teachers send assignments and some English Knowledge (idioms,jokes and humors) to students;(3) Teachers make assessments and evaluations; (4)Students ask questions.

D. Exploratory Learning Based on Web

Web-based exploratory learning is defined as the activity or process in which students search on-line documents to solve problems with the help of teacher. It is a task-oriented, time-constrained process, whose primary goal is performance of the current task, with learning as a secondary aspect. Generally, it consists of five stages: (1) introducing a problem; (2) collecting data or documents related to the problem; (3) interpretating the problem; (4) evaluating the findings; (5) presenting the findings. Web-based exploratory learning is popular with students because it is open, theme-centred, and problem-solving.

Web-based exploratory learning can help develop students' autonomy in learning. By data-collecting, problem-analysing, critical reflection, and decision-making, students will develop a particular kind of psychological satisfaction from the course of exploration. It encourages students to take responsibility for their own learning and take an active approach to the learning task at hand. In order to finish a certain task, students learn to choose from the vast amout of resources availbale. For example, students are asked to find out the stylistic features of a news story. To finish this task, students have to surf the internet to read news on line. They may analyze the stylistic features of several news stories, compare them and describe them so as to reach a final conclusion. They may consult with their peers about their findings. After that, they write down their points of view, ready for future presentation. This kind of learning is more effective than mere lecturing. One the one hand, by news reading, students get to know some new words and phrases. On the other hand, they get to know the stylistic features of news story through exploring. This will be more convincing, as 
"seeing is believing".

E. Collaborative Learning Based on Wireless Network

By definition, collaborative learning is "a coordinated, synchronous activity that is the result of a continued attempt to construct and maintain a shared conception of a problem."[5]A broad definition of collaborative learning is that it is a sitution in which two or more people attempt to learn something together in order that they have a deeper understanding of certain theme.Learners should be quite interactive. The degree of interactivity among peers in not only defined by the frequency of interaction, but also by the extent to which these interactions influence the peers'cognitive process. In order to achieve this goal, teachers may specify rules for collaboration, such as "Everybody in the group should give his or her opinion".

Collaborative learning mode requires learners work as a team. In the course of learning, a learner, surfs the internet to collect information, and processes the information to form his own view. After that, by making interaction and communication, through QQ or BBS, learners can get involved in an active dialogue, ask or discuss questions and express their ideas.Workshop and chat-room are interesting and beneficial for students to express ideas in writing and chatting in English. If proper encouragement and guidance are given by teachers, students can soon transit from dependence to independence, adapt themselves to the new learning environment, and take an active part. This mode of learning can help develop students' cognitive ability and reinforce their team cooperative spirit.

\section{CONCLUSION}

In the modern information age, we move from learners' interaction with computers at a certain time and a fixed place to interaction with other humans freely and openly. M-learning actually opens a new panorama for students. It changes students' learning style. They will not solely depend on their teachers to learn. They construct knowledge by exploring information and moving at their own pace, on their own needs, which lead to the development of critical and independent thinking. They communicate with other people, through synchronous and asynchronous conversation, they encounter different kinds of authentic social situations and discourse communities, thus cultivating their communicative and collaborative competence. In this way, teacher's roles change from a filler and transmitter of knowledge to an organizer and a guider of the teaching process. This kind of learning experience will of course benefit students in their life-long learning, since learning is a ever-lasting process. Through M-learning, even without teachers, people can learn whenver and wherever.

\section{References}

[1] Guidelines for Learning/Teaching/Tutoring in a Mobile Environment. MOBIlearn. October 2003. p. 6. Retrieved June 8, 2009.

[2] Dricoll, M.Blended learning: Let's Get beyond the hype, E-learning, 1 March. Available at: http;//elearning mag.com/Itimagazine. 2002.

[3] Valiathan, P. Blended Learning Models. Available at: www.learning circuits. Com/2002/aug 2002/valiathan. Html.

[4] David, N. Second Language Teaching and Learning [M]. Beijing: Foreign Language Teaching and Research Press, 2001, pp87.

[5] Roschelle, J. \&Teasley S.D. The construction of shared knowledge in collaborative problem solving. In C.E. O’Mally(Ed), Computer-Supported Collaborative Learning. Berlin: Springer-Verlag, 1995, pp.69-197.

[6]http://en.wikipedia.org/wiki/Short_Message_Service. 